\title{
Development and Cross-Validation of Equation for Estimating Percent Body Fat of Korean Adults According to Body Mass Index
}

\author{
Hoyong Sung ${ }^{1, *}$, Junbae Mun² \\ 'Department of Physical Education, Korea Military Academy, Seoul, Korea; ${ }^{2}$ Department of Health and Human Performance, Middle Tennessee State University, \\ Tennessee, USA
}

Background: Using BMI as an independent variable is the easiest way to estimate percent body fat. Thus far, few studies have investigated the development and cross-validation of an equation for estimating the percent body fat of Korean adults according to the BMI. The goals of this study were the development and cross-validation of an equation for estimating the percent fat of representative Korean adults using the BMI.

Methods: Samples were obtained from the Korea National Health and Nutrition Examination Survey between 2008 and 2011. The samples from 2008-2009 and 2010-2011 were labeled as the validation group $(n=10,624)$ and the cross-validation group ( $n=8,291$ ), respectively. The percent fat was measured using dual-energy X-ray absorptiometry, and the body mass index, gender, and age were included as independent variables to estimate the measured percent fat. The coefficient of determination $\left(R^{2}\right)$, standard error of estimation (SEE), and total error (TE) were calculated to examine the accuracy of the developed equation.

Results: The cross-validated $R^{2}$ was 0.731 for Model 1 and 0.735 for Model 2. The SEE was 3.978 for Model 1 and 3.951 for Model 2. The equations developed in this study are more accurate for estimating percent fat of the cross-validation group than those previously published by other researchers.

Conclusion: The newly developed equations are comparatively accurate for the estimation of the percent fat of Korean adults.

Key words: BMI, Cross-validation, Percent fat, Estimation

\author{
Received September 27, 2016 \\ Reviewed November 6, 2016 \\ Accepted December 21, 2016 \\ ${ }^{*}$ Corresponding author \\ Hoyong Sung \\ (iD) \\ http://orcid.org/0000-0002-8325-5206 \\ Department of Physical Education, \\ Korea Military Academy, 574 Hwarang- \\ ro, Nowon-gu, Seoul 01805, Korea \\ Tel: +82-2-2197-2983 \\ Fax: +82-2-2197-6415 \\ E-mail: hoyongsung86@naver.com
}

\section{INTRODUCTION}

Methods for measuring human body components are divided into direct chemical and physical methods using cadavers and indirect methods involving the measurement of the body density. Although the direct methods are more accurate, they have the disadvantage of ethical issues surrounding the dissection of cadavers. Furthermore, dissection and analysis involve numerous people and require considerable time and cost, placing practical limitations on direct methods. ${ }^{1}$ Additionally, people cannot be measured when they are alive, which is the biggest problem. Hence, human body components have most- ly been estimated using indirect measurement methods.

Representative measurement methods that use the volume of the human body to estimate human body components include underwater weighing and plethysmography using a BOD POD device. While accurate estimation relies on the assumption that the densities of lean and fat components are similar between subjects, there are differences in density between individuals or specific racial groups, which can make measurements cumbersome because appropriate estimation equations should be used depending on the characteristics of the subjects. ${ }^{1}$ Both of the aforementioned methods cost a substantial amount of money for laboratory testing and

Copyright (C) 2017 Korean Society for the Study of Obesity

(ㄷ) This is an Open Access article distributed under the terms of the Creative Commons Attribution Non-Commercial License (http://creativecommons.org/licenses/by-nc/4.o/) which permits unrestricted non-commercial use, distribution, and reproduction in any medium, provided the original work is properly cited. 
require qualified personnel; thus, they are difficult to apply without sufficient financial support. There is a more affordable and easier method for estimation, in which skinfolds of specific body parts or the body circumference are measured and then the values are applied in estimation equations. However, the contact between the measuring personnel and the subject can be limited by a gender difference, and the measuring personnel must have abundant experience in measurements and be capable of accurately distinguishing body parts. Other indirect measurement methods include bioelectrical impedance analysis (BIA), which involves estimating the body fat using the principle that electric current flows through fatfree tissue. However, the devices used for this method have a range of validity, and a single device can under- or overestimate depending on the subject. ${ }^{1}$ Technologies such as dual-energy X-ray absorptiometry (DXA), computed tomography, and magnetic resonance imaging can measure human body components more accurately, positioning them between the direct measurement methods, which have limited practicality, and the inaccurate indirect methods, which involve measurement difficulties. However, use of these technologies is normally limited owing to price of the instruments and the exposure to radiation. ${ }^{2}$ Among them, DXA involves measuring the difference in the absorbed radiation between soft tissues and bones and using the measured values to calculate the density. DXA is advantageous because it can estimate human body components with little radiation and in a short time. ${ }^{1,2}$

Among the human body components, the body fat is an index of obesity that is related to various diseases, including hypertension, type 2 diabetes, coronary heart disease, stroke, gallbladder disease, osteoarthritis, breast cancer, uterine cancer, esophageal cancer, colon cancer, pancreatic cancer, and kidney cancer; thus, it must be measured accurately.,4 The prevalence of obesity in Koreans at least 19 years old increased from $26.0 \%$ in 1998 to $31.7 \%$ in 2007 and remained at $31-32 \%$ until $2014 .{ }^{5}$ For physical-education teachers, trainers, professors, and doctors who work in related fields, it is essential to measure the body fat accurately. When it is not feasible to apply the aforementioned measurement methods, an easier method is used, which involves the body mass index (BMI). The BMI equals the weight divided by the square of the height $\left(\mathrm{m}^{2}\right)$ and is used in various fields to evaluate obesity. A higher BMI indicates risk factors for hypertension, hyperlipidemia, and high cholesterol, whereas an extremely low BMI value may indicate risk of death., ${ }^{4,6}$ Because of their ease of measurement, weight and height have been applied not only to evaluate the performance of athletes and the obesity of soldiers and civilians but also as physical data that can affect jobs, salaries, and insurance in the general society. ${ }^{7,8}$ However, because the $\mathrm{BMI}$ is affected by the weight and height, it has a limitation for reflecting body components completely; i.e., individuals with the same BMI can have different percent-fat values. ${ }^{9-11}$ In addition, human body components can differ depending on characteristics such as age, gender, and race, regardless of the BMI. ${ }^{2,7,12,13}$ For these reasons, efforts have been directed towards developing equations for estimating the percent fat in combination with other variables, including age, gender, and race. ${ }^{7}$ However, in most studies, validity tests on the developed equations with subjects besides those employed for the development of the estimation equations were not conducted. With 9,934 Americans who were at least 20 years of age, Cui et al. ${ }^{13}$ tested the validity of 26 estimation equations developed in other studies that used not only the BMI but also various other body measurements for the estimation of the body fat. In Korea, there have been only a few studies involving the development of equations for estimating the percent fat using the BMI and validity tests. ${ }^{6-8,10}$ Although a study was conducted with normal adults as subjects ${ }^{8}$, the body-fat value measured through BIA was used as a dependent variable, and the subjects were limited to residents in Seoul. Thus, the study should be complemented to ensure the validity of the dependent variable and the representativeness of the samples.

The goals of the present study were to develop equations for estimating the percent fat (validation) by using the percent fat as a dependent variable measured with a high-validity method (gold standard) for a representative adult group and to examine the validity of the equations with another representative adult group (cross-validation). The newly developed estimation equations should allow specialists and non-specialists to estimate the percent fat more accurately using variables that can be obtained without special devices.

\section{METHODS}

The Korean Ministry of Health and Welfare and the Korea Centers for Disease Control and Prevention investigated the states of health and nutrition through the Korea National Health \& Nutri- 
tion Examination Survey (KNHANES) with representative samples from the entire Korean population. ${ }^{14}$ The applied sampling methods were three-stage stratified cluster sampling for the years 2008-2009 using data from the "Population and Housing Census" conducted by the National Statistical Office in 2005 and two-stage stratified cluster sampling for the years 2010-2011 using the registered resident population for 2009 and the apartment market research data for 2008. ${ }^{14,15}$ The KNHANES was conducted after approval from the Institutional Review Board of the Korea Centers for Disease Control and Prevention.

\section{Selection of subjects}

The selected subjects were at least 20 years old and participated in the KNHANES from July 2008 to May 2011. The study period was limited to the time during which the percent fat was measured using DXA. The subjects surveyed in 2008-2009 (validation group) were selected for the development of the estimation equations, and those surveyed in 2010-2011 were selected as the cross-validation group to test the validity of the developed estimation equations.

\section{Data processing for analysis}

Raw data for 2008-2011 were downloaded from the KNHANES homepage (http://knhanes.cdc.go.kr/) as a basic survey database (DB) (Year HN_ALL) containing body measurement data by year. Data from bone-density and body-fat test DBs (Year HN_DXA) were combined, and then an integrated $\mathrm{DB}$ was established to perform an integrated analysis of the combined data by year. For complex sample analysis, among a total of 37,753 people, those whose body fat was measured with only DXA were selected for the group of interest $(n=18,915)$.

\section{Study methods}

In the KNHANES, since the second half of 2008, tests were performed in mobile examination vehicles. Body measurements such as height, weight, and percent fat were performed by professional testing teams in independent examination vehicles.

\section{Body measurement}

Regarding the tool used for body measurement, Physical Examination, i.e., the guidebook for the 5th term of the KNHANES
(2010-2012) was downloaded from the KNHANES homepage and referenced. ${ }^{16}$ The heights were measured in $0.1 \mathrm{~cm}$ units using a Seca225 (Seca, Germany), and the weights were measured in $0.1 \mathrm{~kg}$ units using a GL-6000-20 (G-tech, Korea). The body fat was measured using a Discovery-W (Hologic Discovery, USA), which is a bone-density testing device that employs DXA. The BMI was calculated by dividing the weight $(\mathrm{kg})$ by the square of the height $\left(\mathrm{m}^{2}\right)$.

\section{Statistical analysis \\ Data analysis}

The KNHANES samples were extracted by multistage stratified cluster probability sampling, which is a complex sample design method. In accordance with the analysis instructions in the Guidebook for KNHANES Raw Data Analysis (2013), the complex sample analysis method was employed. The weight, stage, and cluster (plot) were considered in order to control the bias in the statistics. ${ }^{17}$ The statistical program was SPSS (VER 21; IBM Corp., Armonk, NY, USA), and the significance level was set as $P=0.05$.

\section{Sample characteristics}

To identify the sample characteristics, the mean, standard error of the mean (SEM), and rate by age group of the major variables were calculated through descriptive statistics of the complex sample analysis and frequency analysis. In the complex sample analysis, a general linear model was applied to identify the mean differences in the major variables between the validation group and the crossvalidation group.

\section{Development of estimation equation}

An equation for estimating the percent fat was developed using the general linear model of the complex sample analysis for the validation group. The percent fat measured via DXA was set as the dependent variable, and the gender, age, and BMI were regarded as basic independent variables. Referring to the various independentvariable types proposed in a preceding $s t u d y^{13}$, estimation equations with a high explanatory power $\left(\mathrm{R}^{2}\right)$ and low standard error of estimation (SEE) and total error (TE) were selected.

\section{Cross-validation}

The newly developed estimation equations were applied to the 
Table 1. Characteristics of samples

\begin{tabular}{|c|c|c|c|c|}
\hline \multirow{2}{*}{ Characteristics } & \multicolumn{2}{|c|}{ Validation group $\left(\mathrm{N}=10,624^{*}\right)$ KNHANES (2008-2009) } & \multicolumn{2}{|c|}{ Cross-validation group $\left(\mathrm{N}=8,291^{*}\right)$ KNHANES (2010-2011) } \\
\hline & Male $\left(n=4,554^{*}\right)$ & Female $\left(n=6,070^{*}\right)$ & Male $\left(n=3,550^{*}\right)$ & Female $\left(\mathrm{n}=4,741^{*}\right)$ \\
\hline Age (yr) & $43.55 \pm 0.393$ & $45.62 \pm 0.376$ & $44.22 \pm 0.487$ & $46.48 \pm 0.483$ \\
\hline $20-39(\%)$ & $41.6 \pm 1.4$ & $38.1 \pm 1.1$ & $39.7 \pm 1.6$ & $35.8 \pm 1.2$ \\
\hline $40-59(\%)$ & $40.5 \pm 1.2$ & $39.0 \pm 0.9$ & $41.8 \pm 1.4$ & $40.3 \pm 1.0$ \\
\hline$\geq 60(\%)$ & $17.8 \pm 0.7$ & $22.9 \pm 0.8$ & $18.5 \pm 1.1$ & $23.8 \pm 1.1$ \\
\hline Height (cm) & $170.53 \pm 0.138$ & $157.18 \pm 0.133$ & $170.94 \pm 0.190$ & $157.16 \pm 0.165$ \\
\hline Weight (kg) & $69.71 \pm 0.213$ & $57.01 \pm 0.162$ & $70.37 \pm 0.318$ & $57.48 \pm 0.224$ \\
\hline $\mathrm{BMI}\left(\mathrm{kg} / \mathrm{m}^{2}\right)$ & $23.93 \pm 0.062$ & $23.08 \pm 0.067$ & $24.04 \pm 0.089$ & $23.30 \pm 0.086$ \\
\hline Percent fat (\%) & $21.13 \pm 0.151$ & $32.17 \pm 0.140$ & $22.36 \pm 0.189$ & $33.34 \pm 0.180$ \\
\hline
\end{tabular}

Data are presented as mean \pm standard error of mean or frequency (\%).

*Unweighted sample size.

KNHANES, Korea national health and nutrition examination survey; BMI, body mass index.

cross-validation group to evaluate their validity. The validity was tested via analysis of the statistics using the SEE $\left(\operatorname{Sy} \sqrt{ } 1-R^{2}\right.$, where Sy is the standard deviation of the measured percent fat, and $\mathrm{R}$ is the multiple correlation coefficient) and TE $\left(\sqrt{ } \Sigma\left(\mathrm{Y}-\mathrm{Y}^{\prime}\right)^{2} / \mathrm{N}\right.$, where $\mathrm{Y}$ is the measured percent fat, and $\mathrm{Y}^{\prime}$ is the percent fat obtained using the estimation equation), as proposed by Kang. ${ }^{18}$

\section{RESULTS}

\section{Characteristics of sample groups}

The mean ages of the males and females were 43.55 and 45.62 years, respectively, for the validation group and 44.22 and 46.48 years, respectively, for the cross-validation group. The mean BMI values for males and females were 23.93 and $23.08 \mathrm{~kg} / \mathrm{m}^{2}$, respectively, for the validation group and 24.04 and $23.30 \mathrm{~kg} / \mathrm{m}^{2}$, respectively, for the cross-validation group. The mean percent fat (\%) was moderately higher for the cross-validation group (22.36\% for males and $33.34 \%$ for females) than for the validation group (21.13\% for males and $32.17 \%$ for females). In the analysis of the mean difference between the validation and cross-validation groups, there were no significant differences in the age, height, weight, or BMI $(P<0.05)$, but there was a significant difference in the percent fat $(\mathrm{f}[1,529]=28.500, P<0.001)($ Table 1$)$.

\section{Development of estimation equations and cross- validation}

Various estimation models were analyzed by referring to the independent variables used for body-fat estimation in a previous
Table 2. Validation of examined models

\begin{tabular}{|c|c|c|c|c|c|}
\hline Included variables & $\begin{array}{c}\text { Mean of } \\
\text { estimated } \\
\text { percent fat }\end{array}$ & $\begin{array}{l}\text { Mean of } \\
\text { measured } \\
\text { percent fat }\end{array}$ & $\mathrm{R}^{2}$ & SEE & TE \\
\hline \multicolumn{6}{|l|}{ Total (male and female) } \\
\hline BMl, gender, age & 27.663 & 27.608 & 0.733 & 3.961 & 3.973 \\
\hline $\mathrm{BMI}$, gender, age, $\mathrm{BM}^{2}$ & 27.656 & & 0.738 & 3.922 & 3.925 \\
\hline $\begin{array}{l}\mathrm{BMl} \text {, gender, age, } \mathrm{BMI}^{2} \text {, } \\
\text { gender } \times \mathrm{BMI}\end{array}$ & 27.655 & & 0.738 & 3.921 & 3.925 \\
\hline $\mathrm{BMI}$, gender, age, gender $\times \mathrm{BMl}$ & 27.662 & & 0.733 & 3.960 & 3.972 \\
\hline BMI, 1/BMl, gender, age & 27.658 & & 0.738 & 3.923 & 3.926 \\
\hline $\mathrm{BMI}, 1 / \mathrm{BMI}$, gender, age, 1/BMI² & 27.656 & & 0.738 & 3.921 & 3.924 \\
\hline 1/BMl, gender, age & 27.656 & & 0.737 & 3.928 & 3.927 \\
\hline${ }^{*} 1 / \mathrm{BMl}$, gender, age, 1/BMl² & 27.657 & & 0.738 & 3.922 & 3.925 \\
\hline \multicolumn{6}{|l|}{ Grouped in gender and age } \\
\hline${ }^{\dagger} 1 / \mathrm{BMl}$, gender and age, $1 / \mathrm{BM}^{2}$ & 27.692 & & 0.742 & 3.896 & 3.892 \\
\hline
\end{tabular}

Models were developed from the validation group.

Age was counted in full.

*The preliminary model (total): ('54.601' for male and ' 66.622 ' for female)

$+0.014 \times$ age $-982.749 \times 1 / \mathrm{BMI}^{+}+192.373 \times 1 / \mathrm{BM}^{2}$

TThe preliminary model (grouped by gender and age):

Male 20-39 yr: 54.614-945.604 × 1/BMI + 3599.326 ×1/BMI ${ }^{2}$

Male 40-59 yr: 54.270-945.604 ×1/BMl + 3599.326 $\times 1 / \mathrm{BMI}^{2}$

Male $\geq 60$ yr: $56.066-945.604 \times 1 / \mathrm{BMI}+3599.326 \times 1 / \mathrm{BM}^{2}$

Female 20-39 yr: 67.086-945.604 $\times 1 / \mathrm{BMl}+3599.326 \times 1 / \mathrm{BM}^{2}$

Female 40-59 yr: 66.379-945.604 ×1/BMl + 3599.326 × 1/BM12

Female $\geq 60$ yr: $67.093-945.604 \times 1 / \mathrm{BMI}+3599.326 \times 1 / \mathrm{BMI}^{2}$

$\mathrm{R}^{2}$ is explanatory power.

$\mathrm{BMI}$, body mass index; SEE, standard error of estimate; TE, total error.

study ${ }^{13}$ The models with a high validity are presented in Table 2. The validity was analyzed for each model, and independent variables were included in each model. Two models exhibited high estimation validity, with a high explanatory power and a low estimation error. The first model used the inverse of the BMI, square of the inverse BMI, gender, and age as independent variables. The other model involved groups considering both gender and age. 
Table 3. Variance analysis of preliminary models

\begin{tabular}{|c|c|c|c|c|}
\hline & \multicolumn{2}{|c|}{ Non-standardized coefficient } & \multirow{2}{*}{$t$} & \multirow{2}{*}{$P$} \\
\hline & B & standard error & & \\
\hline \multicolumn{5}{|l|}{ Model 1} \\
\hline Constant & 66.622 & 1.952 & 34.124 & $<0.001$ \\
\hline Gender (male) & -12.021 & 0.095 & -127.136 & $<0.001$ \\
\hline Gender (female) & - & - & - & - \\
\hline Age & 0.014 & 0.004 & 3.952 & $<0.001$ \\
\hline 1/BMl & -982.749 & 84.997 & -11.562 & $<0.001$ \\
\hline \multirow[t]{2}{*}{ 1/BM" ${ }^{2}$} & 4192.373 & 921.807 & 4.548 & $<0.001$ \\
\hline & & $R^{2}=0.738$ & $F=5770.213$ & $P<0.001$ \\
\hline \multicolumn{5}{|l|}{ Model 2} \\
\hline Constant & 67.093 & 1.878 & 35.733 & $<0.001$ \\
\hline Male 20-39 yr & -12.479 & 0.200 & -62.328 & $<0.001$ \\
\hline Male 40-59 yr & -12.823 & 0.200 & -64.231 & $<0.001$ \\
\hline Male $\geq 60 \mathrm{yr}$ & -11.027 & 0.173 & -63.798 & $<0.001$ \\
\hline Female 20-39 yr & -0.007 & 0.186 & -0.039 & 0.969 \\
\hline Female 40-59 yr & -0.715 & 0.180 & -3.975 & $<0.001$ \\
\hline Female $\geq 60 \mathrm{yr}$ & - & - & - & - \\
\hline 1/BMl & -945.604 & 82.151 & -11.511 & $<0.001$ \\
\hline \multirow[t]{2}{*}{$1 / \mathrm{BM}^{2}$} & 3599.326 & 888.248 & 4.052 & $<0.001$ \\
\hline & & $R^{2}=0.742$ & $F=3498.014$ & $P<0.001$ \\
\hline
\end{tabular}

The preliminary model (total) was represented as Model 1, and that grouped by gender and age was represented as Model 2.

Variance analysis for the preliminary equations of Table 1 are presented.

$\mathrm{R}^{2}$ is explanatory power.

$\mathrm{BMI}$, body mass index.

The equations for these two models were selected to estimate the percent fat for cross-validation.

The results of the variance analysis for the two estimation equations are presented in Table 3. The regression model showed that they had a good statistical fit $(\mathrm{F}=5,770.213, P<0.001$ for Model 1 , $\mathrm{F}=3,498.014, P<0.001$ for Model 2). The explanatory power of the independent variable in the estimation equation for the percent fat was slightly higher for Model 2 (74.2\%) than for Model 1 (73.8\%).

As shown in Table 4, testing the validity of both estimation equations via application to the cross-validation group resulted in accurate estimation of the percent fat measured via DXA. The criteria proposed by Heyward ${ }^{19}$ for a desirable estimation equation are a high validity of the measurement method for dependent variable, a large sample size with at least 100 people, an $\mathrm{R}$ of at least 0.80 , and an SEE less than 4.00. Both of the selected estimation equations satisfied all of these criteria.

Scatter plots comparing the estimated and measured percent fat obtained using DXA are presented in Figs. 1 and 2. As shown in the cross-validation results of Table 4, the estimated mean percent

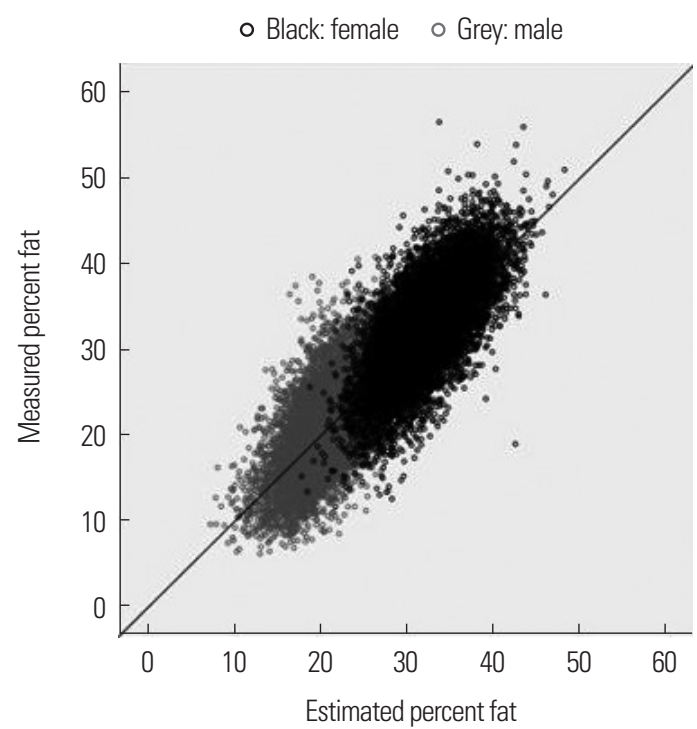

Figure 1. Scatterplots between estimated (x-axis) and measured (y-axis) percent fat (Model 1).

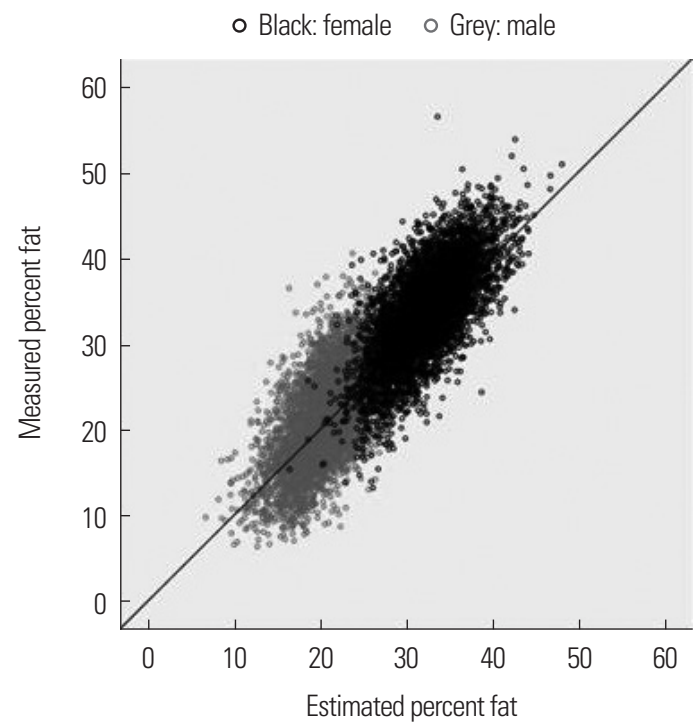

Figure 2. Scatterplots between estimated (x-axis) and measured (y-axis) percent fat (Model 2).

fat values were smaller than the actual values. This is indicated by the figures, where the case group is slightly biased over the graph with $y=0$ and slope $=1$. When the validity of the estimation equations was tested with respect to age after the application of Model 2, the overall $R^{2}$ was $0.705-0.750$. The explanatory power of the estimation equation increased with the age, and the SEE was between 3.777 and 4.052 .

The accuracy of the two selected estimation equations for estimating the percent fat for the cross-validation group was compared 
Table 4. Cross-validation of preliminary models

\begin{tabular}{|c|c|c|c|c|c|}
\hline Models & Mean of estimated percent fat & Mean of measured percent fat & $\mathrm{R}^{2}$ & SEE & TE \\
\hline \multicolumn{6}{|l|}{ Total } \\
\hline Model 1:1/BMl, gender, age, 1/BM| ${ }^{2}$ & 28.737 & 29.226 & 0.731 & 3.978 & 4.114 \\
\hline Model 2: 1/BMI, gender and age, 1/BMI ${ }^{2}$ & 28.782 & & 0.735 & 3.951 & 4.093 \\
\hline \multicolumn{6}{|l|}{ *Group by age } \\
\hline $20-39 \mathrm{yr}$ & 27.983 & 28.299 & 0.705 & 3.985 & 4.137 \\
\hline $40-59 \mathrm{yr}$ & 28.675 & 29.336 & 0.744 & 3.777 & 4.016 \\
\hline$\geq 60 \mathrm{yr}$ & 29.487 & 29.900 & 0.750 & 4.052 & 4.148 \\
\hline
\end{tabular}

The preliminary model (total) was represented as Model 1, and that grouped by gender and age was represented as Model 2.

*Model 2 was applied for the cross-validation in each age group.

$\mathrm{R}^{2}$ is explanatory power.

$\mathrm{BMI}$, body mass index; SEE, standard error of estimate; TE, total error.

Table 5. Comparisons with previously published models

\begin{tabular}{|c|c|c|c|}
\hline Models & $\mathrm{R}^{2}$ & SEE & TE \\
\hline Deurenberg et al. $(1991)^{20}$ & 0.574 & 5.009 & 5.128 \\
\hline Deurenberg et al. $(1998)^{21}$ & 0.612 & 4.780 & 4.887 \\
\hline Gallagher et al. (1996)22 & 0.668 & 4.420 & 4.514 \\
\hline Gallagher et al. $(2000)^{23}$ & 0.668 & 4.419 & 4.495 \\
\hline Gómez-Ambrosi et al. $(2012)^{24}$ & 0.649 & 4.544 & 4.639 \\
\hline Cho $(2006)^{8}$ & 0.655 & 4.509 & 4.743 \\
\hline Current study (Model 1) & 0.731 & 3.978 & 4.114 \\
\hline Current study (Model 2) & 0.735 & 3.951 & 4.093 \\
\hline
\end{tabular}

$R^{2}$ is explanatory power.

SEE, standard error of estimate; TE, total error.

with that of six estimation equations previously developed by other researchers, as shown in Table 5. The two estimation equations had greater explanatory power $\left(\mathrm{R}^{2}=0.731\right.$ for Model 1 and $\mathrm{R}^{2}=0.735$ for Model 2) and smaller prediction errors (SEE $=3.978$ for Model 1 and SEE $=3.951$ for Model 2) than the estimation equations developed by the other researchers. The validity of the estimation equations of the other researchers varied between 0.574 and 0.668 in $\mathrm{R}^{2}$ and between 4.419 and 5.009 in SEE.

An estimation equation was developed by using the entire validation and cross-validation groups $(\mathrm{N}=18,915)$ as samples and considering the independent variables in the two models together, as presented in Table 6 . The $\mathrm{R}^{2}$ of the new equation was slightly superior to those of the two estimation equations in the cross-validation. In contrast, the SEE levels were similar.

\section{DISCUSSION}

The developed equations for estimating the percent fat exhibited explanatory powers as high as $\mathrm{R}^{2}=0.738$ for Model 1 and $\mathrm{R}^{2}=0.742$
Table 6. Development of final models

\begin{tabular}{|c|c|c|c|c|c|}
\hline Models & $\mathrm{R}^{2}$ & SEE & TE & $\mathrm{F}$ & $P$ \\
\hline \multicolumn{6}{|l|}{ Final Model 1} \\
\hline $\begin{array}{l}\text { (Male: } 54.811 \text {, Female: } \\
66.622)+0.010 \times \text { age- } \\
956.110 \times 1 / \mathrm{BMI}_{+} \\
3864.956 \times 1 / \mathrm{BMI}^{2}\end{array}$ & 0.732 & 3.991 & 4.073 & 7790.765 & $<0.001$ \\
\hline \multicolumn{6}{|l|}{ Final Model 2} \\
\hline Male 20-39 yr: 54.484 & 0.736 & 3.965 & 4.045 & 4995.211 & $<0.001$ \\
\hline \multicolumn{6}{|l|}{ Male 40-59 yr: 54.015} \\
\hline \multicolumn{6}{|l|}{ Male $\geq 60$ yr: 55.758} \\
\hline \multicolumn{6}{|l|}{ Female 20-39 yr: 66.831} \\
\hline \multicolumn{6}{|l|}{ Female 40-5 9yr: 66.153} \\
\hline \multicolumn{6}{|l|}{ Female $\geq 60$ yr: 66.744} \\
\hline $\begin{array}{l}-909.814 \times 1 / \mathrm{BMI}_{+} \\
3186.205 \times 11 / \mathrm{BM}^{2}\end{array}$ & & & & & \\
\hline
\end{tabular}

Final models were developed from both validation and cross-validation groups. $\mathrm{R}^{2}$ is explanatory power.

SEE, standard error of estimate; TE, total error.

for Model 2, and application to the cross-validation group resulted in similar explanatory powers of $\mathrm{R}^{2}=0.731$ for Model 1 and $\mathrm{R}^{2}=$ 0.735 for Model 2. The 73.1\% (Model 1) and 73.5\% (Model 2) variance in actual percent fat could be explained by the independent variables. In addition, the error level in the estimation is important. In this study, the SEEs were $\pm 3.978 \%$ (Model 1 ) and $\pm 3.951 \%$ (Model 2) for the estimation of the percent fat. Moreover, the two developed estimation equations had greater explanatory power and smaller prediction errors than equations previously proposed by other researchers, as shown in Table 5, confirming the validity of the two estimation equations.

However, the two estimation equations tended to underestimate the percent fat for the cross-validation group. This is attributed to the significantly lower mean percent fat for the validation group- 
for which the estimation equations were developed-compared with the cross-validation group. Previously, it was suggested that the estimation power is higher in groups having similar characteristics to the validation group. ${ }^{13}$ The differences in the estimation pattern also occurred when the two estimation equations were applied to groups that had a significantly different percent fat from the validation group. These phenomena are "shrinkage" that occurred because of the difference in the percent fat between the group for which the estimation equations were developed and the other group, for which they were applied, and explain why the explanatory powers of the developed estimation equations decreased from $\mathrm{R}^{2}=0.738$ to $\mathrm{R}^{2}=0.731$ for Model 1 and $\mathrm{R}^{2}=0.742$ to $\mathrm{R}^{2}=0.735$ for Model 2. ${ }^{25}$ The shrinkage phenomenon can also be caused by racial differences between the groups, as well as differences in the percent fat. As shown in Table 5, the estimation equations developed with non-Koreans as subjects had less explanatory power for the cross-validation group composed of Korean adults. Among the other six models, those proposed by $\mathrm{Cho}^{8}$ and Gallagher et al. ${ }^{22,23}$ had the greatest explanatory power $\left(\mathrm{R}^{2}=0.655-0.668\right)$, which appears to be because more than 600 Koreans and Japanese were included in the validation groups in each study.

We conclude that gender had a larger effect on the estimation of the percent fat than the BMI and age, on the basis of a previous study ${ }^{12}$ and the physiological theory that females have a higher percent fat than males. Therefore, gender must be considered in every equation for estimating the percent fat. Of the two developed estimation equations, Model 1 was formulated to input each of the dummy variables for the gender and age into the estimation equation, and Model 2 was formulated to apply the dummy variable after consideration of the two variables for the gender and age together with the category division. In conclusion, Model 2 had greater explanatory power and a lower estimation error than Model 1 and is thus likely to have higher estimation accuracy. According to the validity of the estimation equations developed from the validation group, the final model was developed using the same independent variables with all of the subjects in the validation and cross-validation groups. However, its validity was not tested through cross-validation; thus, it may be limited in application.

In this study, we developed equations for estimating the percent fat of Korean adults using the BMI as a predictor. The equations were more accurate than those developed by other researchers. However, the BMI is an external measurement depending on only the height and weight, whereas the percent fat is internal measurement indicating a human body component. Therefore, the developed estimation equations may not be the most accurate methods for estimating the percent fat, because the predictors were selected for simple measurement according to the purpose of this study. To develop more accurate equations for estimating the percent fat, estimation equations using predictors such as the waist circumference, BIA, or skinfolds should be further studied, although these might be more difficult to measure than the BMI. In addition, cross-validation with other sample groups should be performed to improve the validity of the equations developed in this study.

The newly developed estimation equations provide easy methods for estimating the percent fat with no cost. Because of inaccuracies caused by error, they have limitations for use in diagnostic settings, such as obesity diagnosis and examination to determine presence or absence of diseases. However, they can be utilized in smartphone healthcare applications, as well as in vast scale epidemiologic studies, and are thus useful for professionals in settings where the percent fat must be estimated without devices.

\section{CONFLICTS OF INTEREST}

The authors declare no conflict of interest.

\section{ACKNOWLEDGMENTS}

This study was conducted by a research grant (20160514) provided by the Hwarangdae Research Institute of the Korea Military Academy in 2016.

\section{REFERENCES}

1. Katch VL, McArdle WD, Katch FI. Essentials of exercise physiology (translated in Korean). 4th ed. Seoul: Lifescience; 2015.

2. Norgan NG. Laboratory and field measurements of body composition. Public Health Nutr 2005;8:1108-22.

3. Anderson RE. Obesity: etiology, assessment, treatment and prevention (translated in Korean). 1st ed. Seoul: Daehan Media 
Co.; 2006.

4. Dishman RK, Heath GW, Lee IM. Physical activity epidemiology. 2nd ed. Champaign, IL: Human Kinetics; 2013.

5. Ministry of Health and Welfare, Korea Centers for Disease Control and Prevention. 2014 Health Statistics for Korean I: KNHANES (VI-2). 2015 [accessed 2016 Sep 22]; Available from: URL: https://knhanes.cdc.go.kr/knhanes/index.do

6. Cho JH. A cross validation study of developing regression model for estimation of \%body fat from body mass index. Korean Society of Measurement and Evaluation 2007;9:75-85.

7. Kim DY, Chun HJ. Development of prediction equation of \%body fat using BMI and cross-validation for persons with intellectual disability. Journal of Korean Physical Education Association for Girls and Women 2014;28:123-34.

8. Cho JH. Developing regression model for estimation of $\%$ body fat from body mass index. The Korean Journal of Physical Education 2006;45:869-78.

9. Sung SC, Kim HS. Relationship between body mass index and, fat-free mass index and fat-mass index in Korean population. Exerc Sci 2013;22:301-8.

10. Heo JG, Lee JO. Evaluation on the regression model for \% body fat estimated from BMI in elementary students. Korea Sport Res 2006;17:769-80.

11. Russell AR, Esco MR, Lizana SN, Williford HN, Olson MS, Kim $\mathrm{H}$. The accuracy of a BMI-based equation in predicting percent body fat in college-age female athletes. J Strength Cond Res 2011;25 suppl:35-6.

12. Jackson AS, Stanforth PR, Gagnon J, Rankinen T, Leon AS, Rao DC, et al. The effect of sex, age and race on estimating percentage body fat from body mass index: The Heritage Family Study. Int J Obes Relat Metab Disord 2002;26:789-96.

13. Cui Z, Truesdale KP, Cai J, Stevens J. Evaluation of anthropometric equations to assess body fat in adults: NHANES 19992004. Med Sci Sports Exerc 2013;46:1147-58.

14. Ministry of Health and Welfare, Korea Centers for Disease Control and Prevention. KNHANES IV Regulation for Using of Raw Data (2007-2009). 2014 [accessed 2016 Sep 22]; Avail- able from: URL: https://knhanes.cdc.go.kr/knhanes/index.do

15. Ministry of Health and Welfare, Korea Centers for Disease Control and Prevention. KNHANES V Regulation for Using of Raw Data (2010-2012). 2014 [accessed 2016 Sep 22]; Available from: URL: https://knhanes.cdc.go.kr/knhanes/index.do

16. Ministry of Health and Welfare, Korea Centers for Disease Control and Prevention. KNHANES V Regulation for Physical Examination (2010-2012). 2014 [accessed 2016 Sep 22]; Available from: URL: https://knhanes.cdc.go.kr/knhanes/index.do

17. Ministry of Health and Welfare, Korea Centers for Disease Control and Prevention. KNHANES Regulation for Examination of Raw Data 2013. [accessed 2016 Sep 22]; Available from: URL: https://knhanes.cdc.go.kr/knhanes/index.do

18. Kang SJ. Statistics of kinesiology. 2nd ed. Seoul: 21st Publishing; 2015.

19. Heyward V. ASEP methods recommendation: body composition assessment. J Exerc Physiol Online 2001;4:1-12.

20. Deurenberg P, Weststrate JA, Seidell JC. Body mass index as a measure of body fatness: age- and sex-specific prediction formulas. Br J Nutr 1991;65:105-14.

21. Deurenberg P, Yap M, van Staveren WA. Body mass index and percent body fat: a meta analysis among different ethnic groups. Int J Obes Relat Metab Disord 1998;22:1164-71.

22. Gallagher D, Visser M, Sepúlveda D, Pierson RN, Harris T, Heymsfield SB. How useful is body mass index for comparison of body fatness across age, sex, and ethnic groups? Am J Epidemiol 1996;143:228-39.

23. Gallagher D, Heymsfield SB, Heo M, Jebb SA, Murgatroyd PR, Sakamoto Y. Healthy percentage body fat ranges: an approach for developing guidelines based on body mass index. Am J Clin Nutr 2000;72:694-701.

24. Gómez-Ambrosi J, Silva C, Catalán V, Rodríguez A, Galofré JC, Escalada J, et al. Clinical usefulness of a new equation for estimating body fat. Diabetes Care 2012;35:383-8.

25. Vincent WJ, Weir JP. Statistics in kinesiology. 4th ed. Champaign, IL: Human Kinetics; 2012. 